\title{
Perancangan Aplikasi Usaha Mikro Bank Sampah Syariah Menggunakan Aplikasi Android
}

\author{
Rachmat Destriana ${ }^{1}$, Nurdiana Handayani ${ }^{2}$, Syepry Maulana Husain ${ }^{3}$, \\ dan Aditya Tegar Prahara Siswanto ${ }^{4}$ \\ ${ }^{1}$ Fakultas Teknik Program Studi Informatika, Universitas Muhammadiyah Tangerang, \\ J1. Perintis Kemerdekaan 1/33 Cikokol Kota Tangerang, Banten, 15118 \\ e-mail: rachmat.destriana@ft-umt.ac.id ${ }^{1}$,nurdiana.handayani@ft-umt.ac.id ${ }_{2}$ \\ syepry.maulana@ft-umt.ac.id ${ }^{3}$, adit18ia@gmail.com ${ }^{4}$
}

\begin{abstract}
The problem of garbage is a behavioral problem, hence the need for a change in public behavior to discipline throwing garbage in place, and the problem of garbage becomes one of the problems in major cities and other metropolitan cities, including in tangerang area. Household waste is one type of garbage that can cause increasing problems facing the government in dealing with it. Kampung Hijau Kemuning is one of the residential settlements in Binong Village, Curug Sub-District that manages sharia-based waste banks aimed at encouraging environmental rescue to be green, clean, reduce waste and become an additional source of income for the residents of Kampung Hijau Kemuning. In the process of waste bank management requires the development of either the use of computer applications based on android or in the process of financial management that is clean and free from usury in accordance with islamic (sharia) rules. The purpose of this research is to build an Android-based Sharia Waste Bank application with a user friendly view and can assist in the process of managing innovative waste bank activities and become an input to increase the empowerment of micro-enterprises in a community in an activity especially in Tangerang area.
\end{abstract}

Keywords: Sharia Waste Bank; Application; Android; Micro

\begin{abstract}
Abstrak
Masalah sampah adalah masalah perilaku, karenanya diperlukannya perubahan perilaku masyarakat untuk disiplin membuang sampah pada tempatnya, dan masalah sampah menjadi salah satu permasalahan di kota besar dan kota metropolitan lainnya, termasuk di wilayah Tangerang. Sampah rumah tangga adalah salah satu jenis sampah yang bisa menyebabkan bertambahnya masalah yang dihadapi pemerintah dalam menanganinya. Kampung Hijau Kemuning adalah salah satu pemukiman perkampungan di Kelurahan Binong Kecamatan Curug yang melakukan pengelolaan bank sampah yang berbasis syariah yang bertujuan mendorong penyelamatan lingkungan menjadi hijau, bersih, mengurangi sampah dan menjadi sumber penghasilan tambahan untuk warga Kampung Hijau Kemuning. Dalam proses pengelolaan bank sampah memerlukan pengembangan baik penggunaan aplikasi computer yang berbasis android atau dalam proses pengelolaan keuangan yang bersih dan bebas dari riba sesuai dengan kaidah islam (syariah). Tujuan penelitian ini adalah membangun aplikasi Bank Sampah Syariah yang berbasis Android dengan tampilan yang user friendly dan dapat membantu dalam proses pengelolaan kegiatan bank sampah yang inovatif dan menjadi masukan untuk meningkatkan pemberdayaan usaha mikro masyarakat dalam suatu kegiatan khususnya di wilayah Tangerang.
\end{abstract}

Keywords: Bank Sampah Syariah; Aplikasi; Android; Usaha Mikro 


\section{PENDAHULUAN}

Isu sampah telah menjadi perhatian global karena semua negara menghadapi masalah tersebut. Masalah sampah adalah masalah perilaku, karenanya diperlukannya perubahan perilaku masyarakat untuk disiplin membuang sampah pada tempatnya, dan masalah sampah menjadi salah satu permasalahan di kota besar dan kota metropolitan lainnya, termasuk di wilayah Tangerang. Sampah rumah tangga adalah salah satu jenis sampah yang bisa menyebabkan bertambahnya masalah yang dihadapi pemerintah dalam menanganinya. Bupati Tangerang, Ahmed Zaki Iskandar (2019) menyatakan, pihaknya semakin sulit mengendalikan dan mengelola sampah. Di Kabupaten Tangerang, volume sampah rumah tangga tiap hari berkisar 1.500 ton.

Undang-Undang Nomor 18 tahun 2008 tentang Pengelolaan Sampah beserta Peraturan Pemerintah Nomor 81 Tahun 2012 mengamanatkan perlunya perubahan paradigma yang mendasar dalam pengelolaan sampah yaitu dari paradigma kumpulangkut-buang menjadi pengolahan yang bertumpu pada pengurangan sampah dan penanganan sampah yaitu dengan usaha melaksanakan kegiatan pembatasan timbulan sampah, pendauran ulang dan pemanfaatan kembali sampah atau yang lebih dikenal dengan sebutan Reduce, Reuse dan Recycle (3R) melalui upaya-upaya cerdas, efisien dan terprogram. Masyarakat mulai di gerakkan untuk memanfaatkan sampah. Baik sampah kering maupun sampah basah.

Rahmadi dan Mulyani (2016) memaparkan Bank sampah berbasis Syariah sebagai metode atau sarana dalam pengelolaan sampah di wilayah pemukiman atau komplek perumahan. Yang dikelola pada Bank sampah hanya mencakup sampah kering dan masih bisa di daur ulang menjadi barang-barang lain, misalnya plastik, botol, kardus dan barang barang lain yang masing memiliki nilai ekonomi dan sesuai dengan kaidah agama. Sistem pengelolaan keuangan Bank Sampah berbarbasis Syariah, karena semakin banyaknya tuntutan masyarakat akan sistem keuangan yang sesuai kaidah agama karena mayoritas masyarakat Indonesia adalah beragama Islam. Masyarakat menuntut sistem keuangan atau perbankan yang bersih dan bebas dari riba.

Kampung Hijau Kemuning adalah salah satu pemukiman perkampungan di Kelurahan Binong Kecamatan Curug yang melakukan pengelolaan bank sampah yang berbasis syariah yang bertujuan mendorong penyelamatan lingkungan menjadi hijau, bersih, mengurangi sampah dan menjadi sumber penghasilan tambahan untuk warga Kampung Hijau Kemuning. Sampah yang diolah berasal dari limbah rumah tangga (organic atau non organic) yang sudah dipilah-pilah kemudian disetorkan ke pengepul sampah dan sebagian sampah dibuatkan kerajinan dari sampah daur ulang. Hasil dari penjualan sampah unorganic dalam bentuk tabungan nasabah dengan kesepakatan 85\% untuk tabungan nasabah dan 15\% untuk lingkungan serta biaya operasional. Sistem pengelolaan bank sampah yang berjalan saat ini masih bersifat konvensional yaitu proses pencatatan data nasabah, data sampah, data tabungan hasil penjualan sampah masih dicatat dibuku.

Semakin banyaknya tuntutan masyarakat Kampung Hijau Kemuning dalam proses pengelolaan bank sampah sehingga memerlukan pengembangan baik penggunaan aplikasi computer yang berbasis android atau dalam proses pengelolaan keuangan yang bersih dan bebas dari riba sesuai dengan kaidah islam. Kebutuhan akan aplikasi computer yang berbasis android sangat dibutuhkan dalam mengelola administrasi bank sampah syariah baik dalam proses pencatatan data sampah, data nasabah untuk mengetahui saldo tabungan yang bisa diakses dimana saja dan kapan saja menggunakan smartphone. Tujuan penelitian ini adalah membangun aplikasi Bank Sampah Syariah yang berbasis Android dengan tampilan yang user friendly dan dapat membantu dalam proses pengelolaan kegiatan bank sampah yang inovatif dan menjadi masukan untuk meningkatkan pemberdayaan usaha mikro masyarakat dalam suatu kegiatan khususnya 
di wilayah Tangerang.

Pemberdayaan sangatlah penting untuk integral ekonomi rakyat yang mempunyai kedudukan yang penting dan harus diselenggarakan secara menyeluruh, optimal dan berkesinambungan melalui pengembangan iklim yang kondusif, pemberian kesempatan berusaha, dukungan perlindungan dan pengembangan usaha seluas-luasnya, agar dapat menigkatkan kedudukan, peran, dan potensi Usaha Mikro. Dalam mewujudkan pertumbuhan ekonomi, dan dapat meningkatkan pendapatan rakyat, adanya lapangan pekerjaan dan mengurangi kemiskinan.

\section{METODE PENELITIAN}

Metode penelitian yang digunakan adalah metode campuran (kuantitatif dan Kualitiatif), dimana pengumpulan data dilakukan dengan cara metode survei menggunakan daftar peryataan/questioner dan melakukan wawancara langsung ke pihakpihak yang keterkaitan dengan masalah pengelolaan bank sampah syariah.

Ogedebe (2012), menegaskan: Telah ditemukan bahwa dalam analisis dan desain sistem, terutama untuk proses transaksi, di mana dialog yang ditampilkan lebih mudah difahami. Semakin besar interaksi antara komputer dan pengguna, besar pula manfaat yang diperoleh ketika proses pengembangan sistem informasi akan lebih cepat dan membuat pengguna akan lebih interaktif dalam proses pengembangannya. Prototyping dapat diterapkan pada pengembangan sistem kecil maupun besar dengan harapan agar proses pengembangan dapat berjalan dengan baik, tertata serta dapat selesai tepat waktu. Keterlibatan pengguna secara penuh ketika protype terbentuk akan menguntungkan seluruh pihak yang terlibat, bagi pimpinan, pengguna sendiri serta pengembang sistem.

Langkah-langkah dalam prototyping adalah sebagai berikut:

1. Pengumpulan Kebutuhan.

Mengumpulkan kebutuhan melibatkan pertemuan antara pengembang dan pelanggan untuk menentukan keseluruhan tujuan dibuatnya perangkat lunak dan mengidentifikasi kebutuhan berupa garis besar kebutuhan dasar dari sistem yang akan dibuat berupa input sistem, output sistem, proses yang berjalan dalam sistem dan basis data yang digunakan.

\section{Proses Desain}

Desain diperlukan dengan tujuan bagaimana sistem akan memenuhi tujuannya dibuat atau diciptakan. Desain sistem terdiri dari kegiatan dalam mendesain yang hasilnya sebuah spesifikasi dari sistem. Bagian dari desain sistem dapat berupa konsep desain interface, proses dan data dengan tujuan menghasilkan spesifikasi sistem yang sesuai dengan kebutuhan.

3. Membangun prototype.

Desain cepat mengarah ke pembangunan prototype yang nantinya akan menghasilkan paket software, dan produk yang baik sesuai dengan yang diinginkan pelanggan mencangkup: fitur yang user friendly, tampilan input dan output serta laporan yang mudah dimengerti dan mudah dicetak.

4. Evaluasi dan perbaikan.

prototype dievaluasi oleh pengguna dan bagian analis desain dan digunakan untuk menyesuaikan kebutuhan perangkat lunak yang akan dikembangkan. prototype diatur untuk memenuhi kebutuhan pengguna, dan pada saat itu pula pengembang memahami secara lebih jelas dan detil apa yang perlu dilakukannya. 


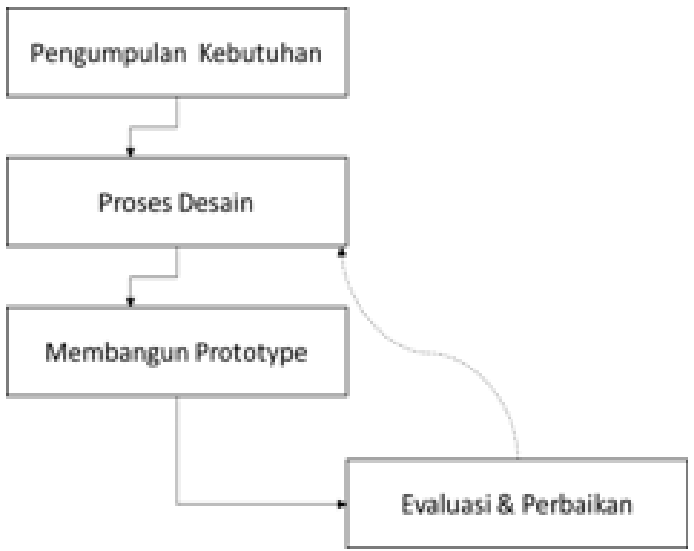

Gambar 1 Langkah-Langkah Prototyping

\section{HASIL DAN PEMBAHASAN}

Dari hasil wawancara dan observasi yang telah dilakukan di Kampung Hijau Kemuning, sesuai dengan pembahasan yang diambil mengenai pengelolaan data bank sampah pada Kampung Hijau Kemuning seperti pendataan transaksi sampah, pemilahan sampah sampai tabungan masih menggunakan semi computer yaitu menggunakan Microsoft Excel.

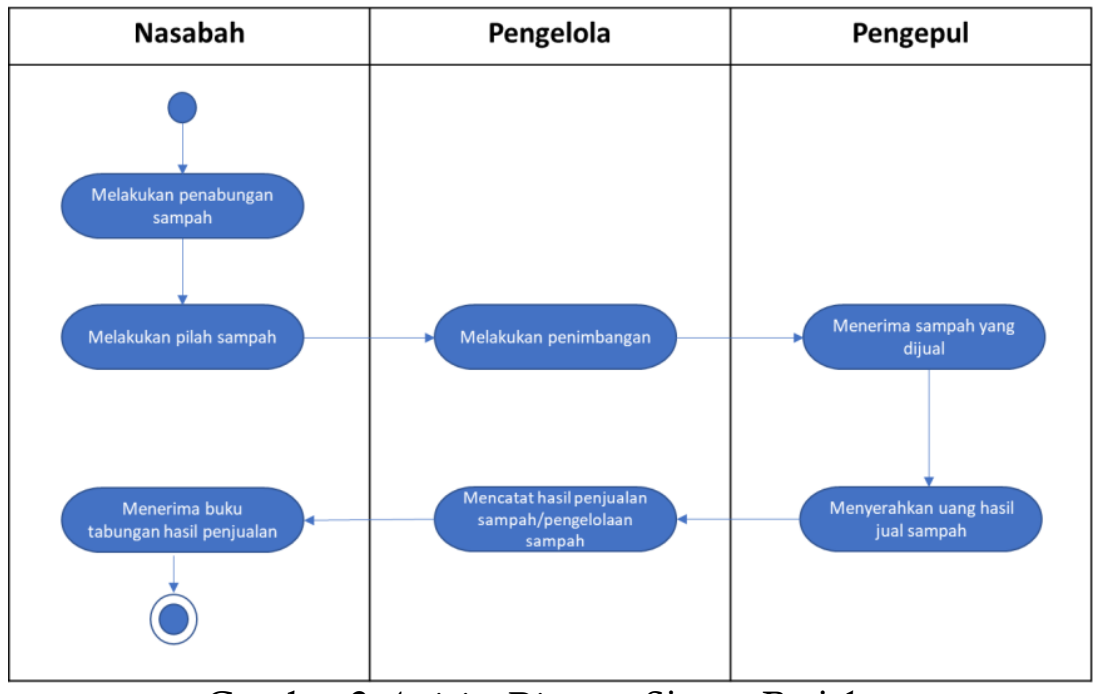

Gambar 2 Activity Diagram Sistem Berjalan 


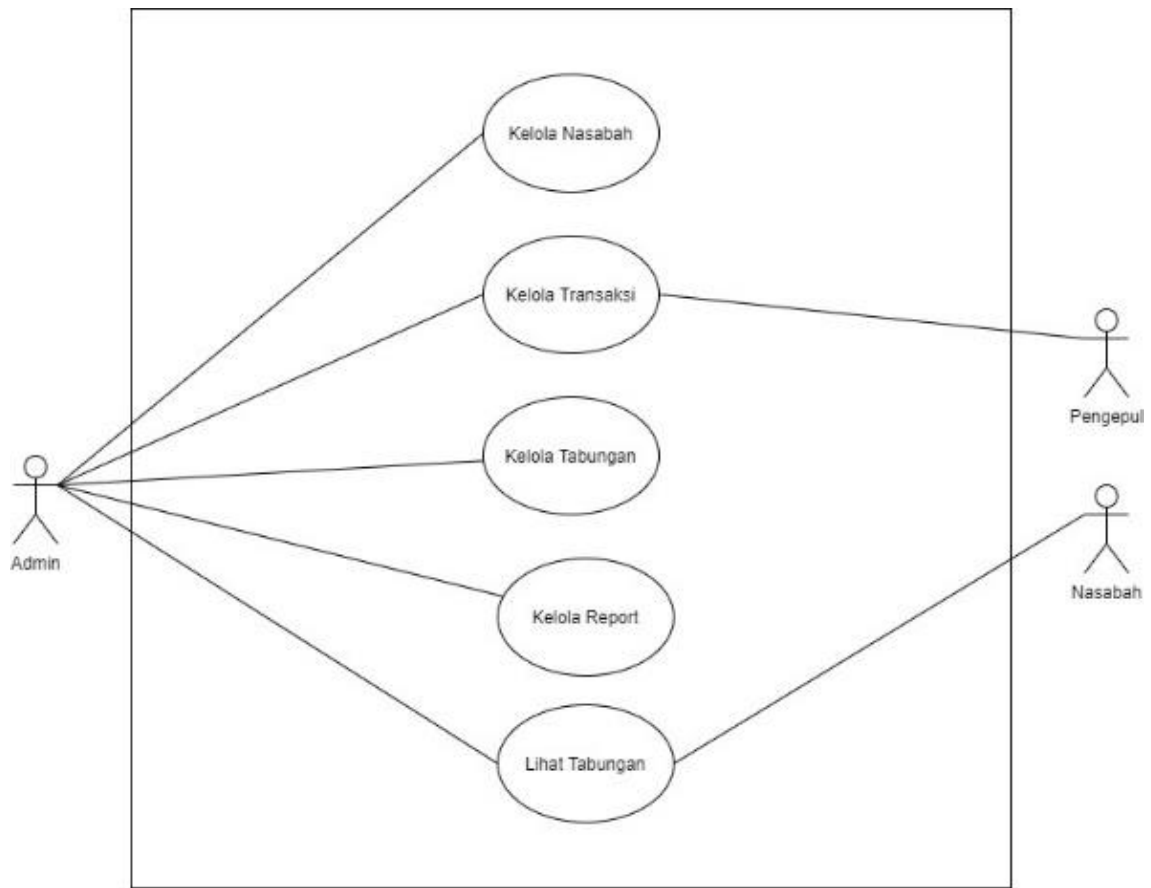

Gambar 3 Use Case Diagram Sistem Berjalan

Kebutuhan yang diperlukan pengguna didapat dari hasil interview yang dilakukan peneliti kepada admin Kampung Hijau Kemuning, yaitu dilakukan analisa kebutuhan sistem yang akan dibuat, peneliti mendapatkan kesimpulan sebagai berikut:

1. Dibutuhkan sebuah sistem informasi yang dapat mengetahui update data sampah maupun saldo tabungan setiap nasabah.

2. Dibutuhkan sistem yang dapat mempermudah dokumentasi kalkulasi data sampah, transaksi sampah sampai saldo tabungan setiap nasabah.

3. Dapat memberikan laporan yang dibutuhkan secara cepat, tepat dan akurat kepada admin maupun nasabah.

\section{A. Rancangan Program Sistem Usulan}

Pemodelan visual yang memungkinkan pengembangan sistem membuat blue print atas visinya dalam bentuk yang baku dengan membuat use case Diagram, Activiy Diagram, Sequence Diagram dan Class Diagram. 
JTS : Jurnal Teknik

1. Use Case Diagram Aplikasi Bank Sampah Syariah Kemuning



Gambar 4 Use Case Diagram Aplikasi Bank Sampah Syariah Kemuning

2. Activity Diagram Aplikasi Bank Sampah Syariah Kemuning

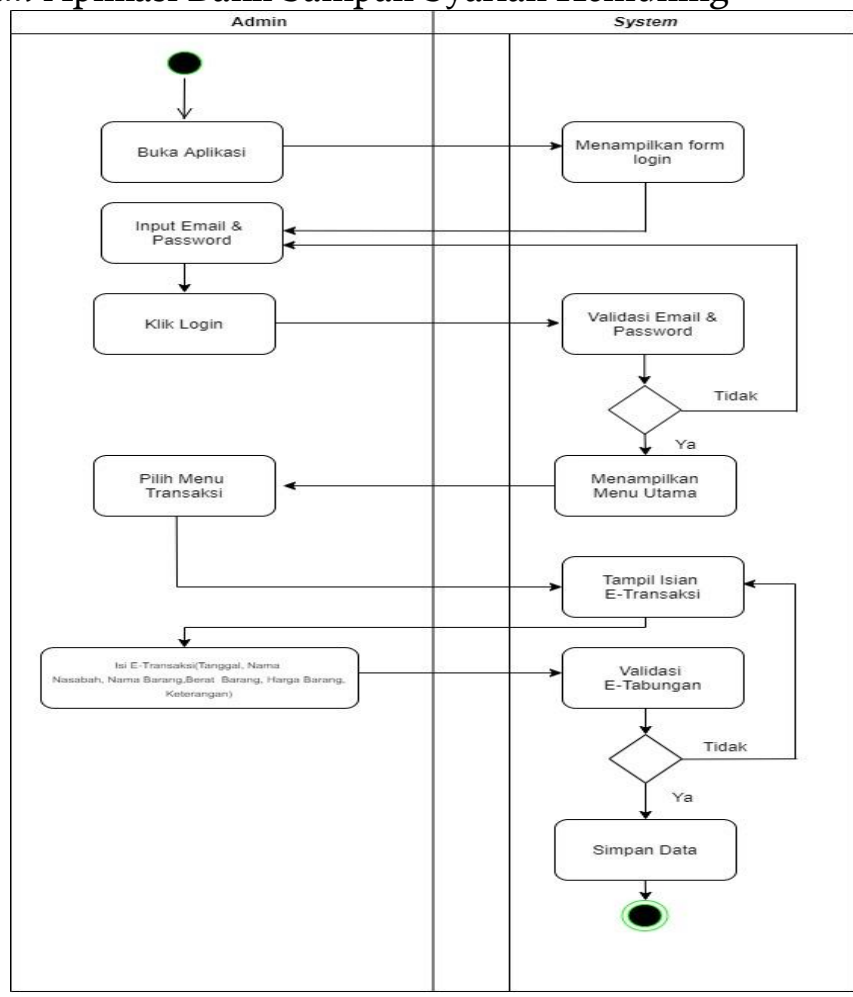

Gambar 5 Activity Diagram Transaksi Penimbangan Sampah 
JTS : Jurnal Teknik

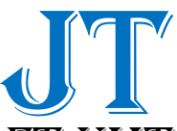

Vol. 9 No. 2 Th. 2020

P-ISSN: 2302-8734

FT UMT

Halaman : 87 - 95

November 2020

3. Sequence Diagram Aplikasi Bank Sampah Syariah Kemuning



Gambar 6 Sequence Diagram Pilah Sampah

\section{B. Hasil Pengembangan Aplikasi Bank Sampah Syariah Kemuning berbasis Android}

Bagian dari desain sistem yaitu berupa konsep desain interface, proses dan data dengan tujuan menghasilkan spesifikasi sistem yang sesuai dengan kebutuhan. Berikut tampilan desain aplikasi Bank Sampah Syariah Kemuning berbasis Andorid.

1. Tampilan Menu Utama

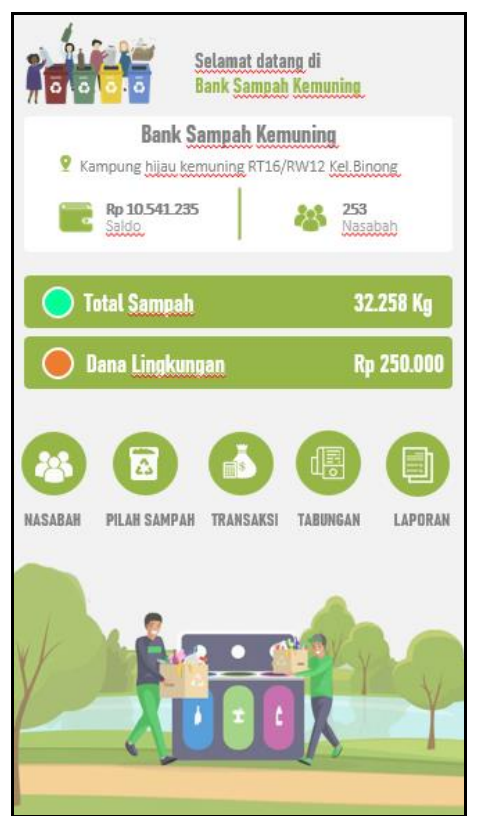

Gambar 7 Tampilan Menu Utama 
JTS : Jurnal Teknik

P-ISSN: 2302-8734

E-ISSN: 2581-0006

2. Tampilan Nasabah
Vol. 9 No. 2 Th. 2020

Halaman : 87 - 95

November 2020

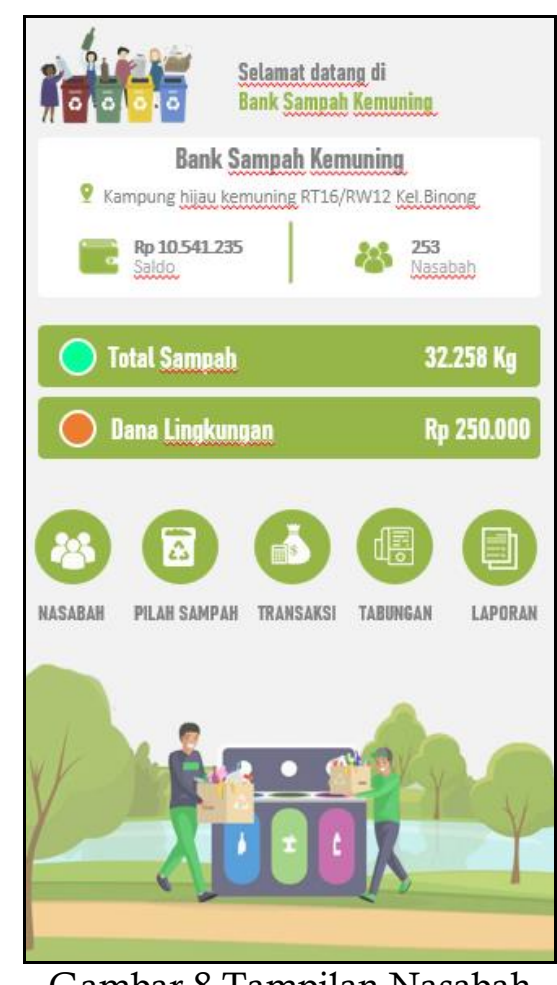

Gambar 8 Tampilan Nasabah

3. Tampilan Transaksi

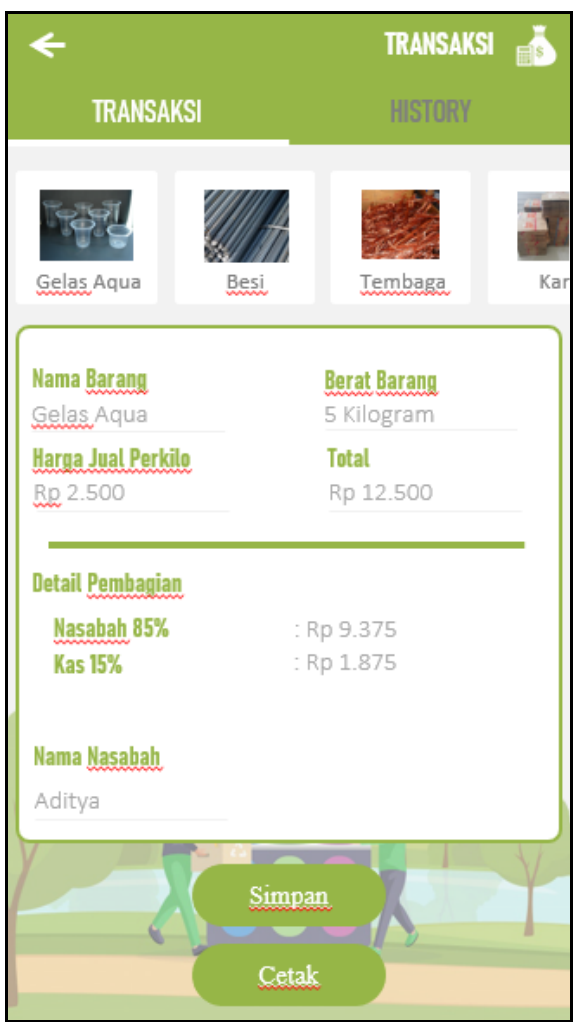

Gambar 9 Tampilan Transaksi 
Kesimpulan penelitiaan Bank Sampah Syariah Berbasis Android Kampung Hijau Kemuning sebagai berikut:

a. Pengelolaan data bank sampah, data tabungan hasil penjualan sampah dan penjualan hasil karya kerajinan dari sampah yang bisa dijadikan nilai value diinput ke Aplikasi Bank Sampah Syariah berbasis Android.

b. Untuk melihat hasil penjualan sampah dan penjualan hasil karya kerajinan dari sampah, nasabah bisa langsung akses ke aplikasi bank sampah syariah berbasis android di smartphone mereka dengan akses sebagai nasabah. Informasi yang ditampilkan pada aplikasi bisa melihat saldo tabungan nasabah, transaksi tabungan, dan data-data yang berhubungan dengan kegiatan bank sampah syariah kampung hijau kemuning.

\section{DAFTAR PUSTAKA}

Referensi yang digunakan dalam penelitian Bank Sampah Syariah berbasis Android Kampung Hijau Kemuning sebagai berikut:

Al Fatta, Hanif. 2013. Indonesian Journal on Networking and Security. Volume 2, No 4. ijns.org, ISSN: 2302-5700.

Permana, Angga Aditya, Nurdiana Handayani, Rohmat Taufiq. 2019. Pembedayaan Masyarakat Desa Melalui Pelatihan Pengelolaan Sukun Menjadi Produk Yang Memiliki Nilai Jual Tinggi. Jurnal Kuat. Vol. 1 No.2 Maret 2019: Hal 105-110

Destriana, R, AA Permana, SD Legawa, H Irawan, 2018, Security system development $\mathrm{f}$ or vehicle using the method of "mail notification" at villa Rizki Ilhami Tangerang, IOP Conference Series: Materials Science and Engineering, Volume 508.

Destriana, R., Taufiq, R., \& Suryana, B. E. (2020). Rancang Bangun Sistem Informasi Document Managemen System Pada Lkp Itc-Pcb Berbasis Web. Jurnal Inovasi Informatika Universitas Pradita, 5(1), 64-71. http://jurnal.pradita.ac.id/index.php/jii/article/view/35.

Indrajani, S. M. (2011). Pengantar dan Sistem Basis Data. Jakarta: PT Elex Media Komputindo Marali, Meilisa Dwiyati, Pradana, Fajar, Priyambadha, Bayu. 2018. Pengembangan Sistem Aplikasi Transaksi Bank Sampah Online Berbasis Web (Studi Kasus: Bank Sampah Malang). Vol. 2, No. 11, hlm. 5644-5650. e-ISSN: 2548-964X.

Pressman. (2012). Metode Waterfall : Definisi, Tahapan, Kelebihan dan Kekurangan. Retrieved from http://www.pengetahuandanteknologi.com: http://www.pengetahuandanteknologi.com/2016/09/metode-waterfall-definisitahapan.htm

Ramadi, Dwi Mulyani. 2016. Model Sistem Informasi Keuangan Bank Sampah Sharia (Micro Finance). Vol. 5, No. 3, ISSN: 1173-1310

Susanto, Stephanus Hermawan. (2011): Mudah Membuat Aplikasi Android, Andi Offset, Yogyakarta. 